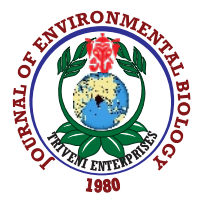

\title{
Accumulation of nutrient contents and biochemical changes in shallot, Allium ascalonicum grown in soil amended with CuO nanoparticle
}

\section{N. Priyanka and P. Venkatachalam*}

Plant Genetic Engineering \& Molecular Biology Laboratory, Department of Biotechnology, School of Bioscience, Periyar University, Salem-636 011, India

*Corresponding Author Email : pvenkat67@yahoo.com

\section{Abstract}

Aim: The aim of the current study was to investigate plants growth, physiological, biochemical and nutrients changes in shallot grown in soil loaded with CuO nanoparticle (CuONPs).

Methodology: The shallot seedlings were treated with increasing doses $\left(25,50,100,200 \mathrm{mg} \mathrm{kg}^{-1}\right)$ of CuONPs; the rate of seedling growth, plant biomass, photosynthetic pigment content level, antioxidant enzyme activities and nutrient elements were estimated and compared with the control.

Results: CuONPs treated plants exhibited increased shoot and root growth $(123.31 \%$ and $184.47 \%$ ) and biomass compared to the control. Also, the level of photosynthetic pigments namely, chlorophyll a (277.24\%), chlorophyll b $(301.42 \%)$ and carotenoids $(104.81 \%)$ increased in the CuONPs exposed plants. The activity of antioxidative enzymes viz. superoxide dismutase (SOD, 382.77-330.29\%), peroxidase (POX, $197.51-166.86 \%$ ) and catalase (CAT, 234$317.35 \%$ ) were found to be significantly high in 100 mg NPs treated plants compared to others. Hence, the nutrient elements in $100 \mathrm{mg}$ NPs treated plants were estimated and found to be higher than control.

Interpretation: Results indicate that the
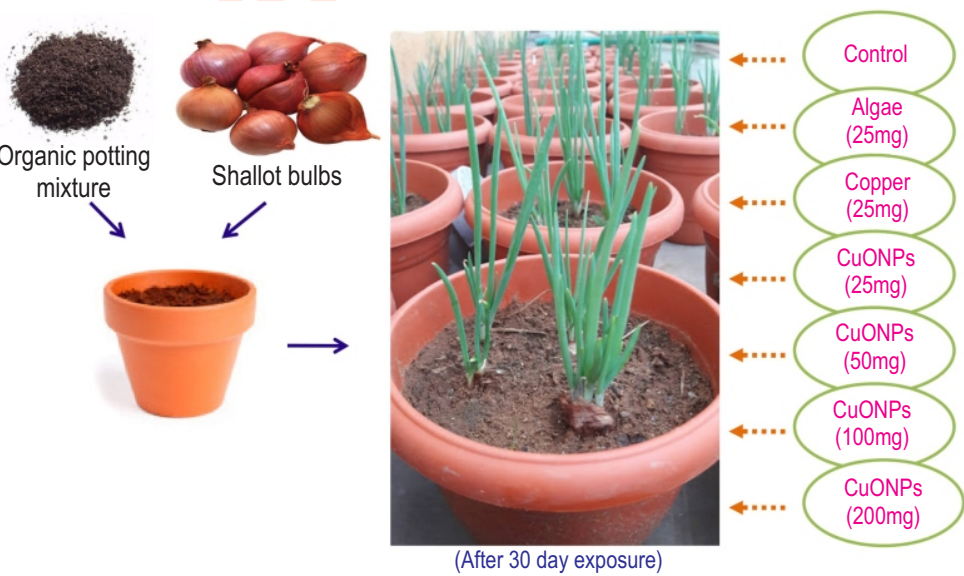

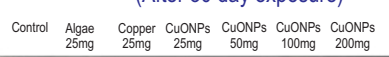

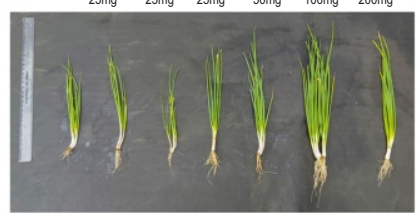

Increase plant growth and biomass Enhance photosynthetic pigment content Stimulate enzyme activities Promote nutrients uptake engineered phycomolecule loaded CuONPs may possibly be used as nanofertilizer to increase crop productivity and it can be used for enhancing growth of agricultural crops in the future.

Key words: Allium ascalonicum, Antioxidative enzyme, Copper oxide nanoparticle, Phycomolecule, Seaweeds

How to cite : Priyanka, N. and P. Venkatachalam: Accumulation of nutrient contents and biochemical changes in shallot, Allium ascalonicum grown in soil amended with CuO nanoparticle. J. Environ. Biol., 41, 563-571 (2020). 


\section{Introduction}

In the global market, nanoparticles (NPs) are tiny materials that are being used in various consumer products, and by 2020 it can rise upto 3 trillion USD by 2020. Currently, more than 1000 viable products that contain NPs are available in the market (Marslin et al., 2017). Bio-synthesis routes offer added benefit, they are easily available, nontoxic, easy handling, rich in nutrient, and cost-friendly (Santhoshkumar et al., 2019). Nanofertilizers are engineered nanomaterials or nano complex (ENPs) responsible for providing essential nutrients to the cultivated crop plants for improving their growth and crop productivity (Liu and Lal, 2015). Based on the type of nutrient requirements, bionanofertilizer can be divided into different categories: macro- and micro- nanofertilizers. Macro-nutrients such as nitrogen $(\mathrm{N})$, magnesium, phosphorus, potassium and calcium, etc., are essential macro elements required for plant growth. The frequently used micronutrients are zinc, copper and silver, etc., for standard plant growth and development. Nanofertilizers play significant role in enhancing the growth of plants as well as crop yield (Ha et al., 2019).

The function of copper nanoparticles as bionanofertilizers and bio-solids agricultural fields can present a feasible way of exposure to the plants (Rawat et al., 2018). Copper improves the production of bioactive compounds, reactive oxygen species, chlorosis, necrosis, altered root system and inhibition of plant growth. Previous studies have reported that $\mathrm{CuO}$ NPs released from various products accumulate in food crops and agricultural soils (Shaw et al., 2014; Nair and Chung, 2014). Copper is an essential crop micronutrient, participating directly in redox enzymes and is involved in chlorophyll synthesis and protein and carbohydrate metabolism (Wang et al., 2019). It is a crucial element when mutual with specific enzymes and proteins that have essential functions in the nutrition and growth of plants; it is concerned with photosynthetic pigment transport, oxidative stress responses, mitochondrial respiration, cell wall metabolism and hormone signalling (DaCosta and Sharma, 2016). Shallot (A. ascalonicum) products are increasing every year in line with the population growth and food industries, in particular instant food using red onions as flavouring agents, but an increase in crop production has not accompanied the rise in demand. This is due to the extensive cultivation of onion and productivity is still low. Alliums are the most crucial horticulture crop worldwide, after tomatoes, with current annual production around 66 million tonnes. Production of onions has increased by more than $25 \%$ in the last ten years (Lemes et al., 2019).

Recently, it has been reported that the application of seaweed extracts on agriculture crops has led to increased percent seed germination, enhanced plant growth and development, resistance against pathogens, pests and also protection against nutrient deficiency. Seaweed based fertilizers have been applied in agricultural land to improve the soil quality management, water use efficiency, nutritional, strategies and drought tolerance etc. (Arioli et al., 2015; Ghaderiardakani et al.,
2019). Different marine environments cover around $70 \%$ of the earth's surface and have remained unexplored. Earlier studies indicate that most algae can perform as biofactories for the production of nanoparticles (Fawcett et al., 2017).

Among the green algae, Caulerpa recemosa and is predominantly well known abundant in the Indo-Pacific region. $C$. racemosa is largely consumed as salads. They are rich in fiber, proteins, minerals (calcium and magnesium), folic acid, ascorbic acid, vitamin A and vitamin B1. Caulerpa possess vitamins, polyunsaturated fatty acids, fibre and bioactive antioxidants (deGaillande et al., 2017; Nagappan and Vairappan, 2014). It is well known that $C$. racemosa produces various secondary metabolites which are involved in defence mechanisms against pathogen infection. In addition, when crude extracts of $C$. racemosa are directly applied on the leaves, the compounds triggered changes in photosynthetic activity. In this context, $C$. racemosa has been selected for the synthesis of nanopaticles and studied for its role on shallot seedlings. In view of the above, the present study mainly focused on the synthesis and characterization of bioengineered nanoparticles loaded with phycomolecules, and to study its growth promoting role on plant growth, physio-chemical changes as well as accumulation of nutrients in shallot plants.

\section{Materials and Methods}

Phycosynthesis and characterization of copper oxide nanoparticle (CuONPs): Caulerpa recemosa, was procured from the coast of Rameswaram, Tamil Nadu, India. It was thoroughly washed with deionized water and powdered after shade drying. The algae powder was boiled under microwave irradiation and the filtrate was mixed with copper sulphate $\left(\mathrm{CuSO}_{4}\right)$ solution, incubated at room temperature to prepare $\mathrm{CuO}$ nanoparticle. The nanoparticle pellets were centrifugated and thoroughly washed. Dried nanoparticles were further characterized by Fourier Transform Infrared Spectroscopy (FTIR), X-ray diffraction (XRD) analysis, Scanning Electron Microscopy (SEM), Energy Dispersive X-ray (EDX) spectra analysis and Dynamic Light Scattering (DLs).

Effect of CuONPs on plant growth and biomass: Mature (30 days) shallot bulbs (A. ascalonicum) were placed in a beaker containing distilled water and mixed for $3 \mathrm{hr}$ until hydrated. Organic potting $(500 \mathrm{~g})$ mix was placed in each pot, creating three replicates per treatment. The seeds were placed about $1.5 \mathrm{~cm}$ deep in the soil. Pots were placed in a greenhouse $\left(25 / 25^{\circ} \mathrm{C}\right.$ day/night temperature). For germination, seeds of same size (3.5 $\mathrm{cm})$ were selected for nanoparticle exposure. For nanoparticle treatment, various doses of $\mathrm{Cu}(25 \mathrm{mg}$ ), CuONPs ( $25 \mathrm{mg}, 50 \mathrm{mg}$, $100 \mathrm{mg}$ and $200 \mathrm{mg}$ ) along with control (water) and algal extract $(25 \mathrm{mg})$ were used in the experiment and treatment was carried out for 30 days. After 30 days of treatment, seedlings were collected for estimating the growth tolerance index, biomass, photosynthetic pigments level and antioxidative enzyme activity. The remaining plants from each pot were maintained for 
maturation. Matured plants were collected and assessed for various biochemical parameters.

Estimation of MDA content: The amount of lipid peroxidase or malondialdehyde (MDA) content in the shoot and root tissues of treated plants were determined following the method of Michael and Krishnaswamy (2011). MDA content was calculated by the following formula: $\mathrm{MDA}\left(\mu \mathrm{mol} \mathrm{g}^{-}\right)=[6.45 \times(\mathrm{A} 532-\mathrm{A} 600)-(0.56$ $\mathrm{xA450)} \mathrm{xVt} / \mathrm{W}]$, where $\mathrm{Vt}=0.0021 ; \mathrm{W}=0.2 \mathrm{~g}$.

Estimation of photosynthetic pigments: The content of chlorophyll a (Chl a), chlorophyll b (Chl b) and carotenoids (Car) was extracted from leaves with $80 \%$ acetone. The amount of chlorophyll $a, b$ and carotenoid content in treated plants was quantified spectrophotometrically at 665,649 and $470 \mathrm{~nm}$ according to Lichtenthaler (1987) and expressed in $\mathrm{mg} \mathrm{g}^{-1}$ f.wt.

Estimation of total soluble protein: Total soluble protein content of shoot and root was determined by Bradford method (1976). Approximately, $100 \mathrm{mg}$ of leaf tissue was homogenized with $1 \mathrm{ml}$ of $0.1 \mathrm{M}$ Tris- $\mathrm{HCl}$ buffer using pre-chill mortar and pestle. The extract was centrifuged (10,000rpm) for $10 \mathrm{~min}$ at $4^{\circ} \mathrm{C}$. The supernatant was transferred to a sterile Oakridge tube and used for the estimation of total soluble protein content. Bovine serum albumin served as standard and protein content was expressed in $\mathrm{mg} \mathrm{g}^{-1}$ f.wt.

Estimation of antioxidative enzyme activity: Fresh leaf and root tissues $(100 \mathrm{mg})$ from treated plants were collected separately and homogenized in a mortar and pestle under icecold conditions with $1.0 \mathrm{ml}$ of extraction buffer, containing $50 \mathrm{mM}$ phosphate buffer (pH-7.5) and $1 \mathrm{mM}$ EDTA. The homogenate was centrifuged (10,000 rpm) for $10 \mathrm{~min}$, and the supernatant was collected and then used to estimate the activity of antioxidative enzymes. Superoxide dismutase (SOD) activity was estimated by measuring its capacity to inhibit the photochemical reduction of nitro-blue tetrazolium (Beauchamp and Firdovich, 1971). The reaction mixture $(3 \mathrm{ml})$ contained $100 \mathrm{mM}$ potassium phosphate buffer (pH 7.8), 3mM EDTA, 200mM methionine, $2.25 \mathrm{mM}$ NBT, $1.5 \mathrm{M}$ sodium carbonate, $60 \mu \mathrm{M}$ riboflavin and enzyme extract. After mixing, the contents in the cuvette were illuminated ( $40 \mathrm{~W}$ light) for $15 \mathrm{~min}$. The enzyme extract was kept in dark and served as blank, while, buffer with no enzyme extract was kept in light served as control. The absorbance was read at $560 \mathrm{~nm}$ against blank using UV-visible spectrophotometer. NBT reduction in the light was recorded in the presence and absence of enzyme extract. SOD activity was expressed as absorbance of control minus absorbance of the sample, giving the total inhibition. One unit of activity denotes the amount of enzyme required for $50 \%$ reduction of NBT under reactive condition.

The activities were expressed in units $\mathrm{mg}^{-1}$ protein ${ }^{-1}$. Catalase (CAT) activity was determined by measuring the decomposition of hydrogen peroxide (Beers and Sizer, 1952). About $100 \mu$ l of enzyme extract was added to the reaction mixture containing $100 \mathrm{mM}$ phosphate buffer $(\mathrm{pH} 7.0)$ and $75 \mathrm{mM} \mathrm{H}_{2} \mathrm{O}_{2}$.
The decrease in the absorbance was recorded at $240 \mathrm{~nm}$. CAT activity was calculated using an extinction coefficient of $39.04 \mathrm{mM}^{-1} \mathrm{~cm}^{-1}$. One unit of CAT activity is defined as the amount required for decomposing $1 \mu \mathrm{mol}$ of $\mathrm{H}_{2} \mathrm{O}_{2}$ (per minute per milligram) protein under assay conditions. Peroxidase (POX) activity was estimated by the method of Zhang et al. (1999). The reaction mixture $(3 \mathrm{ml})$ contained $100 \mathrm{mM}$ potassium phosphate buffer (pH 6.1), 96mM guaiacol, and $12 \mathrm{mM} \mathrm{H}_{2} \mathrm{O}_{2}$, and enzyme extract was used for the estimation of enzyme activity. Oxidation of guaiacol was measured by the increase in absorbance at $470 \mathrm{~nm}$. The activity was calculated using an extinction coefficient of 25.5 $\mathrm{mM}^{-1} \mathrm{~cm}^{-1}$ and expressed in units. One unit of enzyme is the required necessary to decompose $1 \mu \mathrm{mol}$ of substrate $\left(\mathrm{H}_{2} \mathrm{O}_{2}\right)$ per minute.

Effects of nanoparticles on the accumulation of micro and macro elements in shallots: After harvest, shallots were cut into small pieces and oven dried at $60^{\circ} \mathrm{C}$ for $72 \mathrm{hr}$. Dried samples were ground into powder with mortar and pestle, and $0.2 \mathrm{~g}$ of sample was acid-digested with $10 \mathrm{ml}$ of $\mathrm{HNO}_{3}$ and $30 \% \mathrm{H}_{2} \mathrm{O}_{2}$ (Packer et al., 2007; Hong et al., 2015). The temperature was ramped (5 min) from $20^{\circ} \mathrm{C}$ to $100^{\circ} \mathrm{C}$ and held constant for $5 \mathrm{~min}$. Subsequently, the temperature was ramped up to $160^{\circ} \mathrm{C}$ for 5 mins and held constant for $20 \mathrm{~min}$. After digestion, shallot extracts were diluted with $50 \mathrm{ml}$ distilled water for quantification of $\mathrm{Ca}(317.933 \mathrm{~nm}), \mathrm{Cu}$ (327.393nm), Fe (238.204nm), K (766.490nm), Na (589.592 nm), and Zn (206.200 nm) elements using Inductively Coupled Plasmaoptical Emission spectroscopy at their respective wavelengths (ICP-OES, PerkinElmer Optima 5300 DV, Shelton, CT).

Statistical analyses: The replicate data were collected and the results are depicted as mean \pm SE using One-way ANOVA. The significant level was determined at $P \leq 0.05$, and the means were separated using Duncan's Multiple Range Test (IBM, SPSS version 20).

\section{Results and Discussion}

In the present investigation, CuONPs were synthesized from the phycomolecules of $C$. recemosa. The use of algal extracts for synthesis of metallic nanoparticles has several advantages such as simplicity, easy, low-cost and absence of organic solvents and hazardous materials. Biosynthesized CuONPs were further characterized by different techniques viz., FTIR, XRD, EDX and SEM. FT-IR measurements (Fig. 1A) were carried out to confirm the presence of possible bioactive molecules involved in the synthesis of CuONPs. Copper oxide NPs showed peaks at $3438 \mathrm{~cm}^{-1}$-Alcohols, Phenols, $2979 \mathrm{~cm}^{-1}-$ Alkanes, $1414 \mathrm{~cm}^{-1}$ - Aromatics, $1027 \mathrm{~cm}^{-1}-$ Carboxylic acids, $655 \mathrm{~cm}^{-1}$ - Alkenes and $527 \mathrm{~cm}^{-1}$ - Alkyl halides. Similarly, the biosynthesized CuONPs showed peaks at 3885, 1585 and 9983 for alcohols, phenols, aromatic and alkene group in (Nabila et al., 2018). Recently, Ahmaruzzaman (2019) reported that synthesis of copper nanoparticle from Coccinia grandis flower extract showed same alcohols and phenols at $3300 \mathrm{~cm}^{-1}$. XRD analysis (Fig. 1B) confirmed the crystalline nature of engineered 

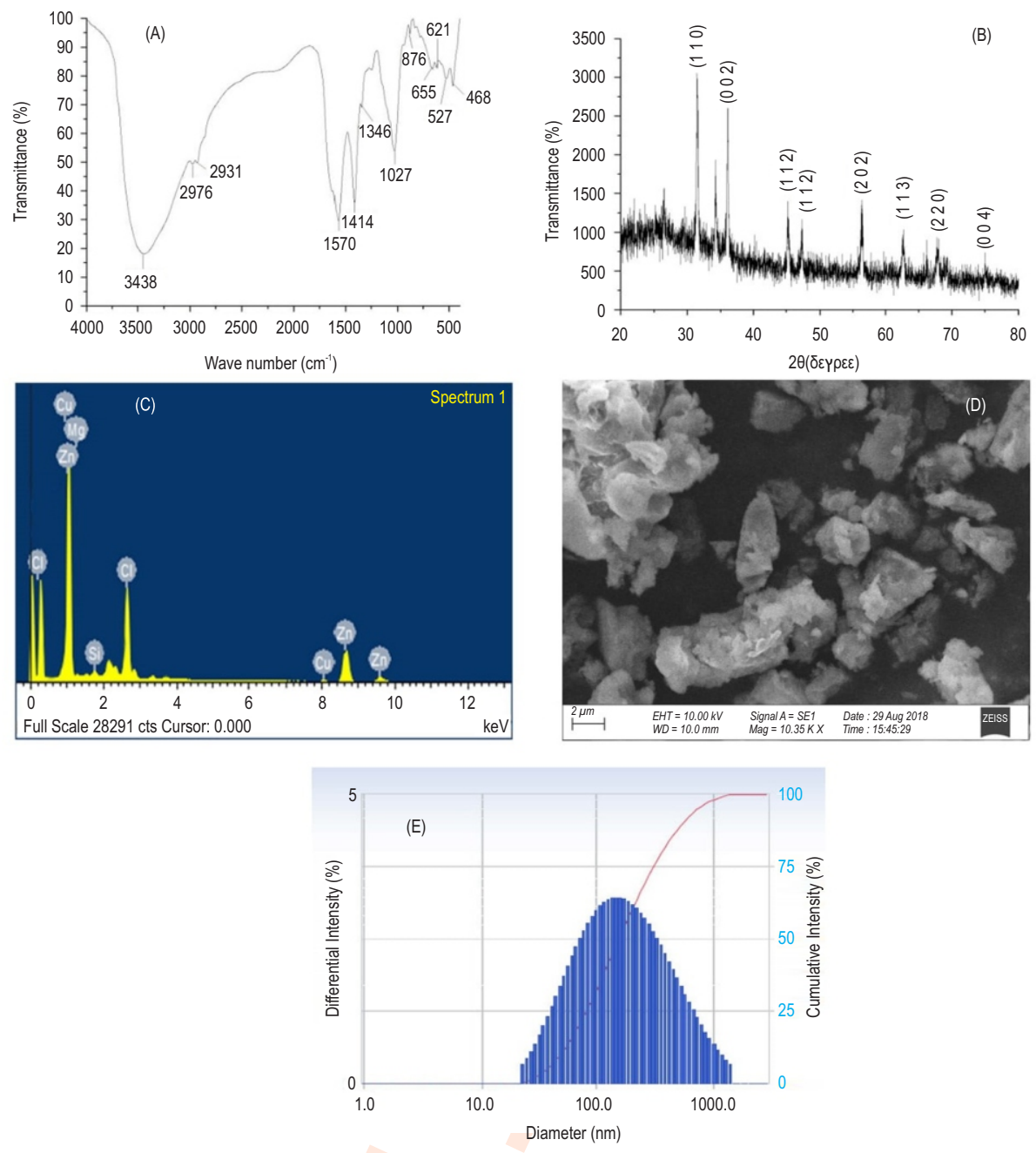

Fig. 1: Characterization of bioengineered CuONPs coated with phycomolecules from marine green algae C. recemosa extract by: (A) FTIR analysis; (B) XRD pattern; (C) EDX spectroscopy analysis; (D) SEM analysis and (E) DLs.

nanoparticles and produced strong intense peaks at a spectrum of $2 \theta$ values ranging from 20 to 80 . The peaks were corresponding to the angles $(110,002,112,202,113,220$ and 004) referred to the JCPDS No: 96-901-5925. Similarly, Saravanakumar et al. (2019) reported the synthesis of CuONPs (JCPDS. 96-901-5925) using Trichoderma asperellum extract. Scanning Electron Microscopy revealed (Fig. 1C) that the $\mathrm{CuO}$ nanoparticles were spherical and crystal shaped at $2 \mu \mathrm{m}$. Fig. 1 (D) confirmed the presence of copper element due to the surface plasma resonance of CuONPs showing strong peak at 1 and 8 $\mathrm{keV}$. Dynamic Light Scattering particle size analysis of phycomolecule coated nanoparticles unveiled size ranging from 23.4 to $149.5 \mathrm{~nm}$ in CuONPs (Fig. 1E).

In order to evaluate the stimulated growth in nanoparticle treated shallots, various physio-chemical characteristics such as biomass, seedling shoot and root length were studied. The shoot and root lengths increased by 123.31 and $184.47 \%$, respectively, at $100 \mathrm{mg}$ NPs treated plants over control. The fresh and dry biomass of plants increased significantly with higher concentrations of $\mathrm{CuO}$ nanoparticles. Plants treated with CuONPs at $100 \mathrm{mg} \mathrm{kg}^{-1}$ had enhanced fresh biomass of shoot and root by 311.99 and $727 \%$ (Fig. 2B), and dry biomass of shoot and root by $485.41-636.36 \%$ (Fig. 2 C), respectively, than control. Similar results were also reported earlier by Prasad et al. (2012) in Arachis hypogaea, where a significant increase in root length, seed germination percentage, seedling vigour index and yield of NPs were observed. In contrast, Adams et al. (2017) reported that CuONPs inhibited root elongation at 10,30, and $300 \mathrm{mg} \mathrm{Cu} \mathrm{kg}^{-1}$ sand. Recent study have shown that $A$. hypogaea seedlings grown under various doses of NPs treatment showed highest germination percentages at 300 ppm treatment (Rajiv and Vanathi, 2018). Interestingly, nanoparticles have been found to inhibit bacterial infection and promote growth in rice (Ibrahim et 


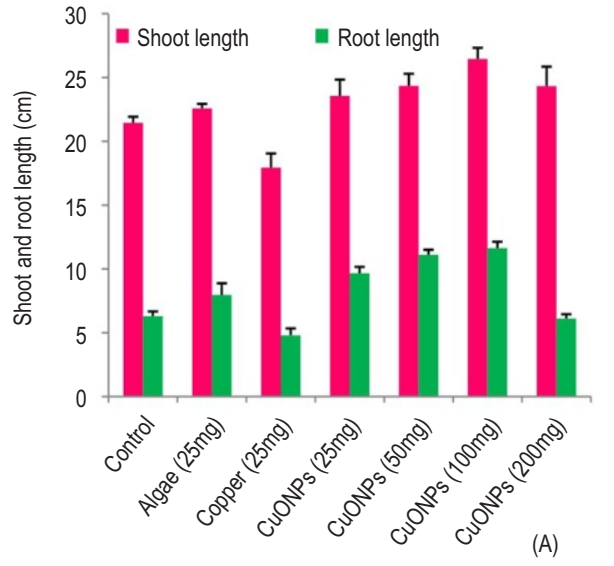

Concentration $\left(\mathrm{mg} \mathrm{l}^{-1}\right)$

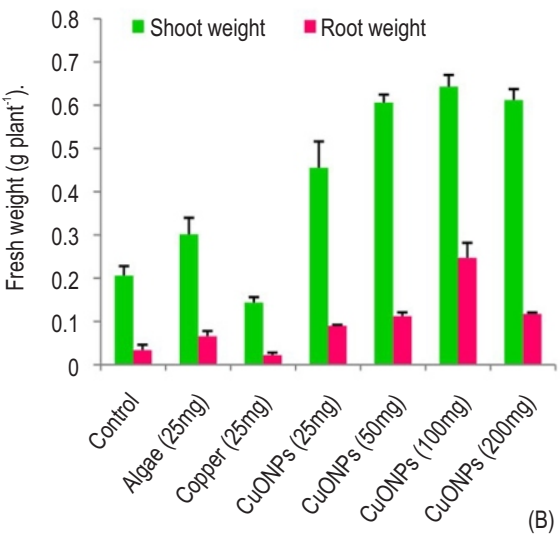

Concentration $\left(\mathrm{mg} \mathrm{l}^{-1}\right)$

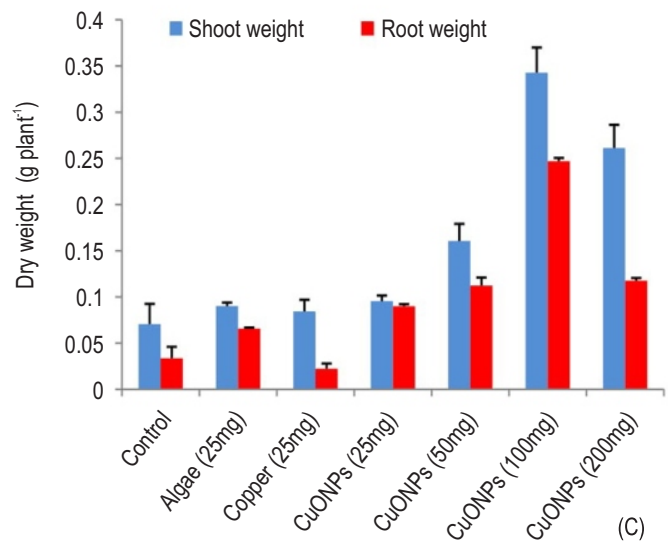

Concentrations $\left(\mathrm{mg} \mathrm{l}^{-1}\right)$

Fig. 2: Effects of $\mathrm{CuO}$ nanoparticle with different doses on: (A) shoot and root length; (B) Fresh weight and (C) dry weight of shallots. Values are mean of three replicates \pm SE. Means following within each row having same letter are not statistically significant to new Duncan's Multiple Range Test.

al., 2019). It was observed that the CuONPs treated plants showed a significant decrease in MDA contents with increasing concentrations of $100 \mathrm{mg}$ CuONPs. Venkatachalam et al. (2017) demonstrated that exposure of NPs in L. leucocephala decreased the lipid peroxidation level in roots. Recent studies have shown that $\mathrm{CuO}$ NPs at different concentrations can inhibit MDA contents (Wang et al., 2019). Photosynthetic pigments play an important role in plant growth and crop productivity. NPs exposure had significantly affected the chlorophyll a, chlorophyll $b$ and carotenoid contents and the findings were compared to the untreated control (Fig. 3B).

The increased percentage of photosynthetic pigment was directly correlated to the CuONPs concentrations used in the experiment. In $100 \mathrm{mg} \mathrm{kg}^{-1} \mathrm{NPs}$ treated plants, the chlorophyll a, chlorophyll b and carotenoid contents was $277.24 \%, 301.42 \%$ and $104.81 \%$, respectively. Earlier studies have indicated that metal oxide nanoparticles were presumed to be involved in energy transfer of isolated reaction centres, consequently altering the photosynthetic efficiency, photochemical fluorescence and quantum yield in plants (Rico et al., 2015). Faizan et al. (2017) reported that NPs treatments at different durations enhanced chlorophyll content in tomato plants. Sujatha and Vijayalakshmi (2013) reported the positive role of Caulerpa racemosa extract as evidenced by increase in dry weight, leaf area index, total chlorophyll and yield attributes against unsprayed and water sprayed plants. In addition, exposure to 3\% Caulerpa racemosa extract highly accelerated the growth that attributes increased seed yield (74\%) compared to control in black gram.

In the present study, the protein content (Fig. 3C) showed significant increase up to $100 \mathrm{mg} \mathrm{kg}^{-1}$ of CuONPs (178.49$163.35 \%$ ) concentration in shallot plants over the control. Priyanka and Venkatachalam (2016) reported that exposure of NPs caused oxidative stress in cotton, which was evidenced by increased protein level, ranging from $126-165.4 \%$ in the treated 

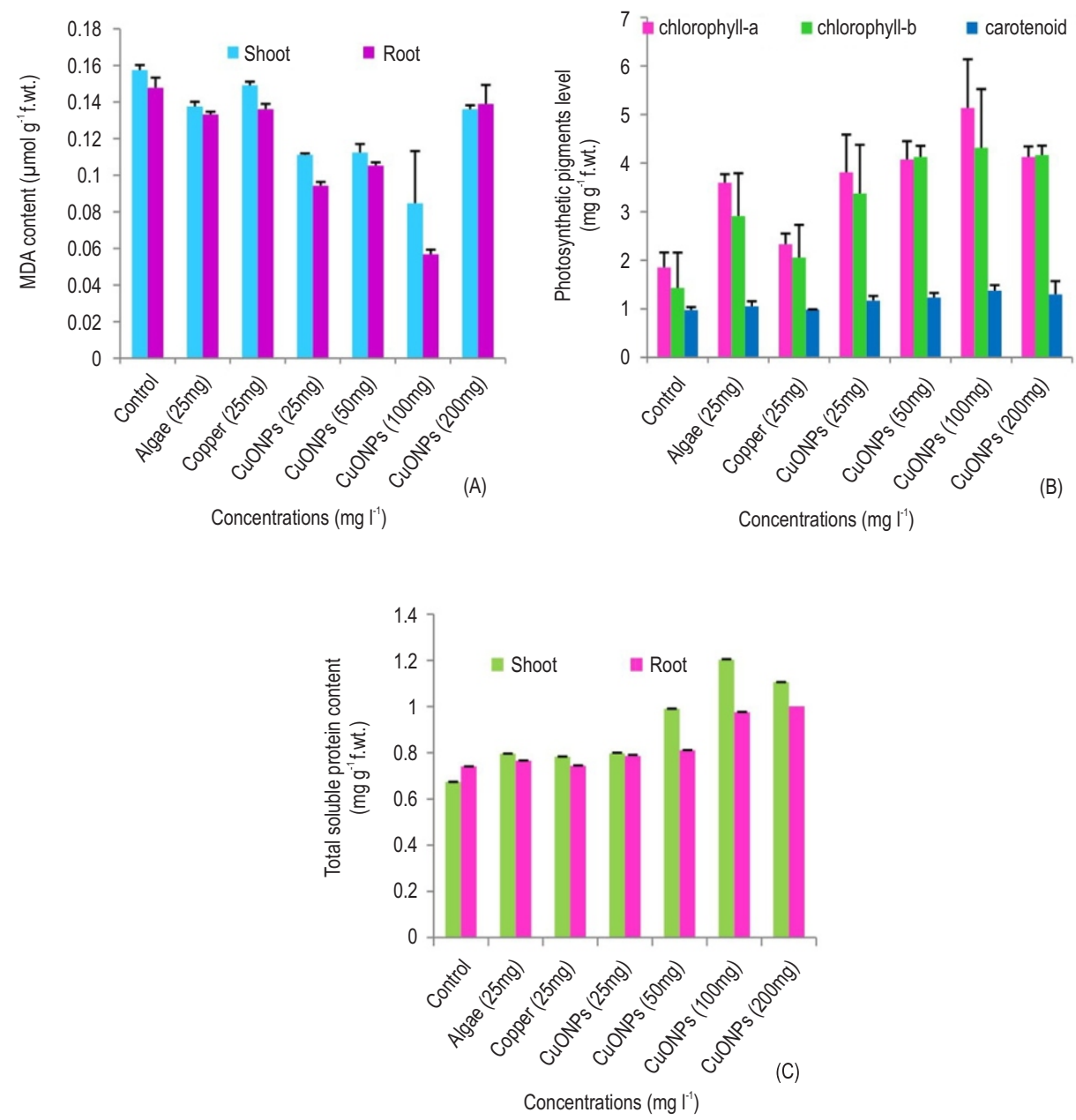

Fig. 3: Effects of CuO nanoparticle with different doses on: (A) MDA content; (B) Photosynthetic pigment (Chl a, Chl b and carotenoids); (C) Protein content in leaves of shallots. Values are mean of three replicates \pm SE. Means following within each row having same letter are not statistically significant to new Duncan's Multiple Range Test.

plants. Tarafdar et al. (2014) reported that the synthesized nanoparticles had significantly increased the total soluble leaf protein content $(38.7 \%)$ in pearl millet. To overcome stress, different antioxidative enzymes were synthesized to quench excess ROS species. The perusal of results showed that SOD activity (Fig. 4A) in shoot and root tissues increased to 152.17$119.42 \%, 161.64-139.76 \%, 197.51-166.86 \%$ and $165.84-$ $125.79 \%$ treated with 25, 50, 100, $200 \mathrm{mg} \mathrm{kg}^{-1}$ CuONPs. Exposure of NPs significantly enhanced the CAT and POX activities in leaves and root of shallots. Seed treated with $100 \mathrm{mg}$ $\mathrm{kg}^{-1}$ CuONPs enhanced the CATactivity (Fig. 4B) by 234.06 and $317.35 \%$, while it decreased at higher doses.

Peroxidase activity in plants treated with $100 \mathrm{mg} \mathrm{kg}^{-1}$ CuONPs showed enhanced activity by 197.51 and $166.86 \%$ (Fig. 4 (C). Similarly, CuO NPs exposure enhanced the antioxidant activities in Stevia rebaudiana (Javed et al. 2017). Expression of Enzyme related genes such as $\mathrm{Cu}, \mathrm{Zn}-\mathrm{SOD}, \mathrm{CAT}$ and APX were
Table. 1: Nutritional elements (micro and macro nutrients) altered shallots (A. ascalonicum) in soil amended with $100 \mathrm{mg}$ CuONPs

\begin{tabular}{lll}
\hline & \multicolumn{2}{c}{ Concentration (mg kg } \\
\cline { 2 - 3 } & Control (mg kg $^{-1}$ soil) & $\begin{array}{l}100 \mathrm{mg} \mathrm{CuONPs}^{-1} \\
\text { ( } \mathrm{mg} \mathrm{kg}^{-1} \text { soil) }\end{array}$ \\
\hline Macronutrients & $16.8833 \pm 0.08838$ & $48.01 \pm 0.1267$ \\
$\mathrm{Ca}$ & $8.8073 \pm 0.40045$ & $34.068 \pm 0.0816$ \\
$\mathrm{~K}$ & $10.74 \pm 0.18330$ & $30.9133 \pm 0.16586$ \\
$\mathrm{Na}$ & & \\
$\mathrm{Macronutrients}$ & $0.1377 \pm 0.00769$ & $14.9667 \pm 0.9135$ \\
$\mathrm{Cu}$ & $1.4103 \pm 0.01146$ & $3.522 \pm 0.5474$ \\
$\mathrm{Fe}$ & $0.0137 \pm 0.00498$ & $0.0213 \pm 0.00669$ \\
$\mathrm{Zn}$ &
\end{tabular}

Values are mean of three replicates \pm S.E. Means following within each row having same letter are not statistically significant to new Duncan's Multiple Range Test 

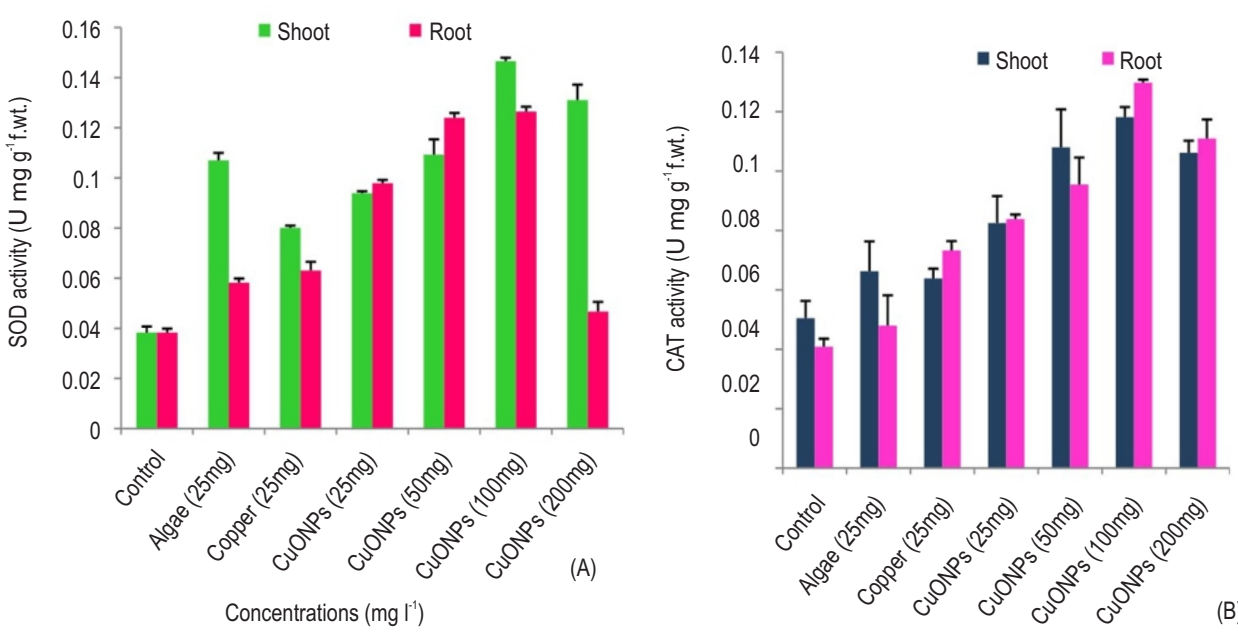

Concentrations $\left(\mathrm{mgl}^{-1}\right)$

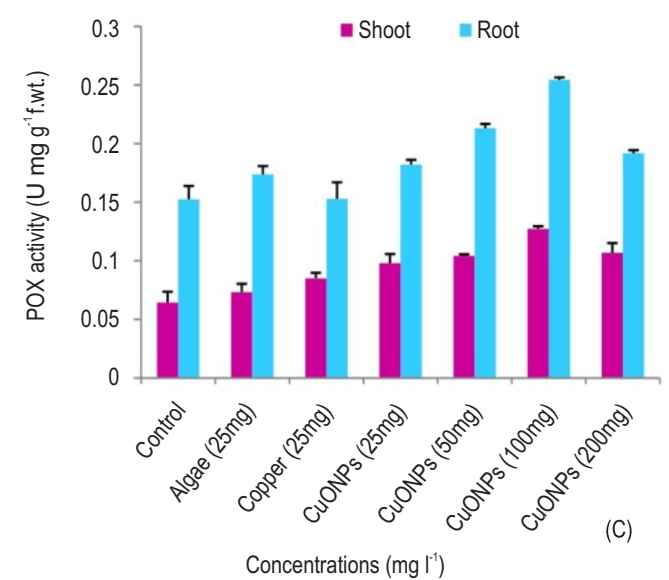

Fig. 4: Impact of CuO nanoparticle with different doses on antioxidative enzymes of shallots: (A) SOD; (B) CAT and (C) POX. Values are mean of three replicates \pm S.E. Means following within each row having same letter are not statistically significant to new Duncan's Multiple Range Test.

regulated in CuONPs-treated plants of chickpea (Nari and Chung, 2015). Cu and Zn-nanoparticles had increased the activity of antioxidative enzymes (Taran et al., 2017). Recently, nanoparticles have been found to reduce oxidative stress in Capsicum chinense, wheat and tomato plants, (Israel GarcíaLópez et al., 2018; Hussain et al., 2018; Quiterio-Gutiérrez et al., 2019). López-Vargas et al. (2019) observed that SOD and CAT enzymes showed a significant increase in Cu NPs treated tomato.

Nutrient accumulation in control and nanoparticle treated plants were estimated and found to be comparatively high in treated plants. Micro and macro elements are essential components of functional and structural molecules of living organisms. Plants accumulate these nutrients, mainly through roots, from the soil or growth medium nutrient. Earlier studies suggest that copper NPs have altered the mineral nutritional levels in many crop plants; CuONPs increased $\mathrm{Cu}, \mathrm{P}$ and $\mathrm{S}$ by $100 \%$, $50 \%$ and $20 \%$, respectively, in alfalfa plants (Hong et al., 2015).
Results reveal that foliar application of NPs treatments had significantly increased the nutrients content (N, P, K, Fe, Zn and $\mathrm{Cu}$ ) in the leaves of sweet basil as compared to control leaves (EIKereti et al., 2013). In conclusion, the results of this study suggest that lower concentration CuO NPs can be used as nanofertilizer for enhancing plant growth and biomass of economically importantagricultural crops.

\section{Acknowledgments}

Authors are grateful to Periyar University for providing financial support inform of university research fellowship (URF).

\section{References}

Adams, J., M. Wright, H. Wagner, J. Valiente, D. Britt and A. Anderson: Cu from dissolution of $\mathrm{CuO}$ nanoparticles signals changes in root morphology. Plant Physiol. Biochem., 110, 108-117(2017). 
Ahmaruzzaman, M.: Removal of perilous nitrocompound from aqueous phase using biogenic copper nanoparticles as a catalyst. Indian J. Chemi. Technol., 25, 561-564 (2019).

Arioli, T., S. Mattner and P.C. Wand Winberg: Applications of seaweed extracts in Australian agriculture: Past, present and future. J. Appl. Phycol., 27, 2007-2015(2015).

Beauchamp, C. and I. Fridovich: Superoxide dismutase: Improved assays and an assay applicable to acrylamide gels. Anal. Biochem., 44, 276-287(1971).

Beers, R.F. and I.W. Sizer: A spectrophotometric method for measuring the breakdown of hydrogen peroxide by catalase. J. Biol. Chem., 195, 133-140 (1952).

Bradford, M.M.: A rapid and sensitive method for the quantitation of microgram quantities of protein utilizing the principle of protein-dye binding. Anal. Biochem., 72, 248-254 (1976).

Da Costa, M.V.J. and P.K. Sharma: Effect of copper oxide nanoparticles on growth, morphology, photosynthesis, and antioxidant response in Oryza sativa. Photosynthetica, 54, 110-119 (2016).

de Gaillande, C., C. Payri, G. Remoissenet and M. Zubia: Caulerpa consumption, nutritional value and farming in the Indo-Pacific region. J. Appl. Phycol., 29, 2249-2266 (2017)

El-Kereti, M.A., S.A. El-feky, M.A. S Khater, Y. Osman and E.S.A. ElSherbini: $\mathrm{ZnO}$ nanofertilizer and $\mathrm{He} \mathrm{Ne}$ laser irradiation for promoting growth and yield of sweet basil plant. Rec. Pate. Food Nutr. Agri., 5, 169-181 (2013).

Faizan, M., A. Faraz, M. Yusuf, S. T.Khan and S. Hayat: Zinc oxide nanoparticle-mediated changes in photosynthetic efficiency and antioxidant system of tomato plants. Photosynthetica, 56, 678-686 (2018).

Fawcett, D., J. J. Verduin, M. Shah, S. B. Sharma and G. E. J. Poinern: A review of current research into the biogenic synthesis of metal and metal oxide nanoparticles via marine algae and seagrasses. $J$ Nanosci, Volume 2017, Article ID 8013850 (2017).

Ghaderiardakani, F., E. Collas D.K. Damiano,K. Tagg, N.S. Graham and J.C. Coates: Effects of green seaweed extract on Arabidopsis early development suggest roles for hormone signalling in plant responses to algal fertilisers. Sci. Rep., 9, 1983 (2019).

Ha, N.M.C., T.H. Nguyen, S.L. Wang and A.D. Nguyen: Preparation of NPK nanofertilizer based on chitosan nanoparticles and its effect on biophysical characteristics and growth of coffee in green house. Res. Chemi. Intermedi., 45, 51-63 (2019).

Hong, J., C.M. Rico, L. Zhao, A.S. Adeleye, A.A. Keller, J.R. PeraltaVidea and J.L. Gardea-Torresdey: Toxic effects of copper-based nanoparticles or compounds to lettuce (Lactuca sativa) and alfalfa (Medicago sativa). Environ. Sci: Processes Impacts, 17, 177-185 (2015).

Hussain, A., S. Ali, M. Rizwan, M.Z. Rehman, M.R. Javed, M. Imran and R. Nazir: Zinc oxide nanoparticles alter the wheat physiological response and reduce the cadmium uptake by plants. Environ. Poll., 242, 1518-1526 (2018).

Ibrahim, E., H. Fouad, M. Zhang, Y. Zhang, W. Qiu, C. Yan and J. Chen: Biosynthesis of silver nanoparticles using endophytic bacteria and their role in inhibition of rice pathogenic bacteria and plant growth promotion. RSCAdvances, 9, 29293-29299 (2019).

Israel García-López, J., R.H. Lira-Saldivar, F. Zavala-García, E. Olivares-Sáenz, G. Niño-Medina, N. Angélica Ruiz-Torres and E. Díaz-Barriga: Effects of zinc oxide nanoparticles on growth and antioxidant enzymes of Capsicum chinense. Toxicol. Environ. Chem., 100, 560-572.(2018).

Javed, R., M. Usman, B. Yücesan, M. Zia and E. Gürel: Effect of zinc oxide $(\mathrm{ZnO})$ nanoparticles on physiology and steviol glycosides production in micropropagated shoots of Stevia rebaudiana Bertoni. Plant Physiol. Biochem., 110, 94-99 (2017).
Lemes, L., A.F.A. de Andrade and R. Loyola: Spatial priorities for agricultural development in the Brazilian Cerrado: May economy and conservation coexist?. Biodivers. Conserv., 1-18 (2019) doi. org/10.1007/s10531-019-01719-6.

Lichtenthaler, H.K.: Chlorophylls and Carotenoids: Pigments of Photosynthetic Biomembranes. Meth. Enzymol., 148, 350-382 (1987)

Liu, R. and R. Lal: Potentials of engineered nanoparticles as fertilizers for increasing agronomic productions. Sci. Total Environ., 514, 131-139 (2015).

López-Vargas, E., H. Ortega-Ortíz, G. Cadenas-Pliego, K. de Alba Romenus, M. Cabrera de la Fuente, A. Benavides-Mendoza and A. Juárez-Maldonado: Foliar application of copper nanoparticles increases the fruit quality and the content of bioactive compounds in tomatoes. Appl. Sci., 8, 1020 (2018).

Marslin, G., C.J. Sheeba and G. Franklin: Nanoparticles alter secondary metabolism in plants via ROS burst. Fronti. Plant Sci., 19, 8:832 (2017).

Michael, P.I. and M. Krishnaswamy: The effect of zinc stress combined with high irradiance stress on membrane damage and antioxidative response in bean seedlings. Environ. Experi. Bot., 74, 171-177 (2011).

Nabila, M.I. and K. Kannabiran: Biosynthesis, characterization and antibacterial activity of copper oxide nanoparticles (CuO NPs) from actinomycetes. Biocatal.Agricul. Biotechnol., 15, 56-62 (2018).

Nagappan, T. and C.S. Vairappan: Nutritional and bioactive properties of three edible species of green algae, genus Caulerpa (Caulerpaceae). J. App. Phycol., 26, 1019-1027 (2014).

Nair, P.M.G. and I.M Chung: Impact of copper oxide nanoparticles exposure on Arabidopsis thaliana growth, root system development, root lignificaion, and molecular level changes. Environ. Sci. Pollu. Res., 21, 12709-12722 (2014).

Packer, A.P., D. Lariviere, C. Li, M. Chen, A. Fawcett K. Nielsen and L.S. Erhardt: Validation of an inductively coupled plasma mass spectrometry (ICP-MS) method for the determination of cerium, strontium, and titanium in ceramic materials used in radiological dispersal devices (RDDs). Analytica Chimica. Acta, 588, 166-172 (2007).

Prasad, T.N.V.K.V., P. Sudhakar, Y. Sreenivasulu, P. Latha V. Munaswamy, K.R. Reddy and T. Pradeep: Effect of nanoscale zinc oxide particles on the germination, growth and yield of peanut. $J$. Plant Nutrit., 35, 905-927 (2012).

Priyanka, N. and P. Venkatachalam: Biofabricated zinc oxide nanoparticles coated with phycomolecules as novel micronutrient catalysts for stimulating plant growth of cotton. Adv. Nat. Sci: Nanosci. Nanotechnol., 7, 045018 (2016).

Quiterio-Gutiérrez, T., H. Ortega-Ortiz, G. Cadenas-Pliego, A. D. Hernández-Fuentes, A. Sandoval-Rangel, A. BenavidesMendoza and A. Juárez-Maldonado: The application of selenium and copper nanoparticles modifies the biochemical responses of tomato plants under stress by Alternaria solani. Int. J. Mol. Sci., 20, $1950(2019)$

Rajiv, P. and P. Vanathi: Effect of Parthenium based vermicompost and zinc oxide nanoparticles on growth and yield of Arachis hypogaea L. in zinc deficient soil. Biocat. Agri. Biotechnol., 13, 251-257 (2018).

Rawat, S., V.L. Pullagurala, M. Hernandez-Molina, Y. Sun, G. Niu, J.A. Hernandez-Viezcas, J.R. Peralta-Videa, and J.L. GardeaTorresdey: Impacts of copper oxide nanoparticles on bell pepper (Capsicum annum L.) plants: A full life cycle study. Environ. Sci. Nano., 5, 83-95 (2018).

Rico C.M., A.C. Barrios, W. Tan, R. Rubenecia, S.C. Lee, A. VarelaRamirez and J.L. Gardea-Torresdey: Physiological and 
biochemical response of soil-grown barley (Hordeum vulgare L.) to cerium oxide nanoparticles. Envir. Sci. Pollut. Res., 22, 1055110558 (2015).

Rizwan, M., S. Ali, B. Ali, M. Adrees, M. Arshad, A. Hussain and A.A. Waris: Zinc and iron oxide nanoparticles improved the plant growth and reduced the oxidative stress and cadmium concentration in wheat. Chemosphere, 214, 269-277.(2019).

Santhoshkumar, J., H. Agarwal, S. Menon, S. Rajeshkumar and S.V. Kumar: A biological synthesis of copper nanoparticles and its potential applications. In: Green Synthesis, Characterization and Application of Nanoparticles. Micro and Nano Technologies, pp. 199-221 (2019).

Saravanakumar, K., S. Shanmugam, N.B. Varukattu, D. MubarakAli, K. Kathiresan and M.H. Wang: Biosynthesis and characterization of copper oxide nanoparticles from indigenous fungi and its effect of photothermolysis on human lung carcinoma. J. Photochem. Photobiol., 190, 103-109 (2019).

Shaw, A.K., S. Ghosh, H.M. Kalaji, K. Bosa, M. Brestic, M. Zivcak and Z. Hossain: Nano-CuO stress induced modulation of antioxidative defense and photosynthetic performance of Syrian barley (Hordeum vulgare L.). Environ. Experi. Bot., 102, 37-47 (2014).

Sujatha, K. and V. Vijayalakshmi: Foliar application of Caulerpa racemosa seaweed extract as bio-stimulant for enhancement of growth and yield of blackgram (Vigna mungo L.). Int. J. Adv. Res. Tech., 2, 216-230 (2013).

Tarafdar, J.C., R. Raliya, H. Mahawar and I. Rathore: Development of zinc nanofertilizer to enhance crop production in pearl millet (Pennisetum americanum). Agricul. Res., 3, 257-262 (2014).

Taran, N., V. Storozhenko, N. Svietlova, L. Batsmanova, V. Shvartau and M. Kovalenko: Effect of zinc and copper nanoparticles on drought resistance of wheat seedlings. Nanoscale. Res. Let., 12, 60 (2017).

Venkatachalam, P., M. Jayaraj, R. Manikandan, N. Geetha, E.R. Rene, N.C. Sharma and S.V. Sahi: Zinc oxide nanoparticles (ZnONPs) alleviate heavy metal-induced toxicity in Leucaena leucocephala seedlings: A physiochemical analysis. Plant Physiol. Biochem., 110,59-69 (2017).

Wang, Y., Y. Lin, Y. Xu, Y. Yin, H. Guo and W. Du: Divergence in response of lettuce (var. ramosa Hort.) to copper oxide nanoparticles/ microparticles as potential agricultural fertilizer. Environ. Pollut. Bioavailab., 31, 80-84 (2019).

Zhang, Z., Z. Wang and R. Lin: Purification and some properties of a peroxidase from tartary buckwheat bran. Fagopyrum, 16, 57-60 (1999). 